\section{Mathematics in Art}

1 $\mathrm{n}$ the late nineteenth and early twentieth centuries, artists were fascinated by non-Euclidean geometry and the fourth dimension. This interest in mathematics provoked them to look at the world in new ways and to record their observations in paintings.

Robert Delaunay rejoiced in the visual impact of color. In his Rythme: Joie de Vivre of 1931, the circles vividly represent the halos around glowing electric street lights. He and his contemporaries were aware of the new geometries and the writings of Poincaré. Interpreting this work, Delaunay remarked, "All is halo," adding that he had never seen a straight line in his life.

In his Broadway Boogie-Woogie of 1943, Piet Mondrian created spatial ambiguity by means of colored lines in rectangular arrangements. He shared other artists' enthusiasm for portraying the fourth dimension, and his earlier paintings feature white and colored rectangles separated by straight black lines, with the white spaces representing the fourth dimension.

Victor Vasarely was influenced by Mondrian's works and studied colors, perception, and illusion. In Vega-Chess, he created an optical illusion by repeating the same motif over and over again; because of its fourfold rotational symmetry, this painting can be hung with any side at the top. His Tridimensional Design is similarly based on symmetry.

Bridget Riley has always made great play of geometry in her paintings, which feature black-and-white geometrical designs, colored displays of parallelograms and other tilings, and colored parallel lines, as in her World of Music.

Optical art-now universally abbreviated to op artarose in the mid-1960s, through the work of Vasarely, Riley, and others. It originated in the abstract geometric designs of Matisse, Kandinsky, and Mondrian and in the constructivist approach of Germany's Bauhaus School and is based on geometric patterns arranged to give the illusion of movement, such as Youri Messen-Jaschin's dramatic arrangement of concentric circles and vertical lines.

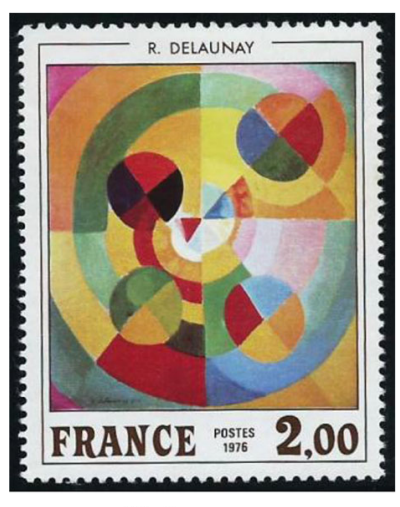

Delaunay

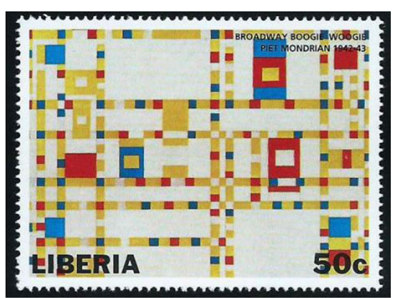

Mondrian

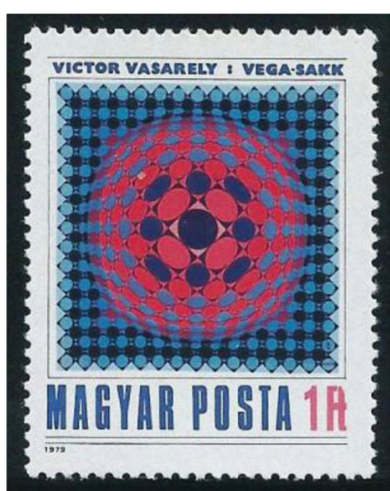

Vasarely 1

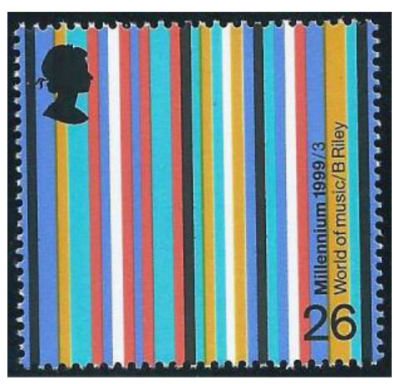

Riley

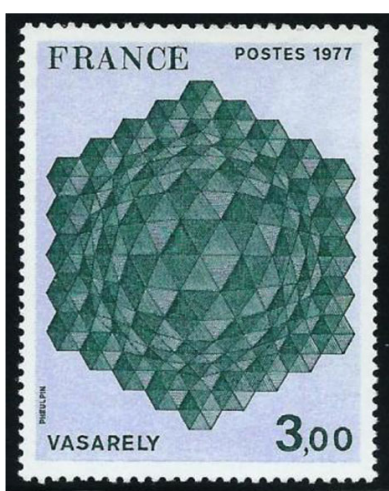

Vasarely 2

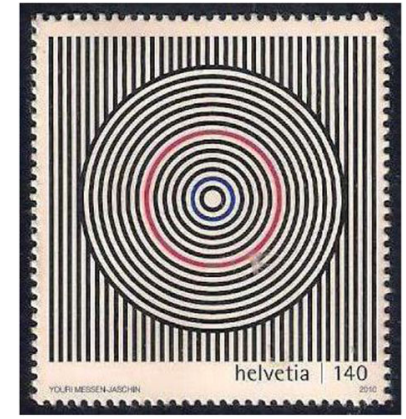

Messen-Jaschin

> Mathematical Institute, Andrew Wiles Building, University of Oxford, UK

e-mail: r.j.wilson@open.ac.uk 